Jan Furch

https://doi.org/10.21278/TOF.444004719

ISSN 1333-1124

eISSN 1849-1391

\title{
THE MODEL PREDICTION OF LIFE CYCLE OWNERSHIP COSTS OF SPECIAL MOTOR VEHICLES
}

\begin{abstract}
Summary
The paper deals with the prediction of life cycle costs related to special motor vehicles. In the first part, there is an analysis of the applied commercial software programs used for calculating and predicting the life cycle cost of vehicles. Next, there is a description of risks which might occur when calculating the life cycle cost and of the possible risk management. In the second part of the paper it is suggested that the motor vehicle life cycle cost can be predicted based on accurate data which are generally difficult to obtain, e.g. failure intensity $z(t)$ or mean time between failures (MTBFs) used for calculating the cost after maintenance. The final part includes a proposal for the prediction of the ownership life cycle cost which consists of the operating and maintenance costs of special motor vehicles. This proposal is based on the company logistic information system, which at regular intervals assesses special vehicle life cycle cost during operation and maintenance. Under special motor vehicles here we understand the vehicles which are equipped with a chassis and a special vehicle superstructure which consumes operation units and on which maintenance is performed. Such vehicles are used in the construction or agricultural industry as well as in the military environment. The paper focuses on the design of a prediction model of the ownership life cycle cost of the military environment, where a relevant military logistic information system is used.
\end{abstract}

Key words: $\quad$ motor vehicle life cycle cost, prediction model, life cycle cost prediction, ownership cost, operating cost, preventive maintenance cost, corrective maintenance cost

\section{Introduction}

A life cycle cost (LCC) analysis is an economic analysis aimed at assessing overall costs of a product purchase, ownership and decommissioning. This analysis provides important input data in the decision-making process during the design, development, usage and disposal phases [1], [2]. The producers can optimize their designs by evaluating alternatives and carrying out a study on cost and benefit optimization. In order to optimize life cycle costs they can evaluate different strategies of operation, maintenance and decommissioning. The life cycle cost analysis might be used efficiently when evaluating the costs of specific activities, for example while evaluating different concepts and approaches to maintenance, solving problems of a specific part of a product, or dealing with problems connected with only a selected product life cycle phase or phases [3], [4] and [5]. The life cycle cost analysis provides a framework for specifying the estimated total incremental cost of developing, producing, using and retiring a particular item [1]. 
The life cycle cost analysis is used for optimizing a design concept and is most effective in the early life cycle phases. However, the analysis can be also updated and used during subsequent life cycle phases in order to discover areas of significant cost uncertainty and risk. The selected life cycle costs might be used for calculating life time or setting an optimum interval of product maintenance [6].

At present, there is a tendency to predict life cycle costs before a product is in operation. For this prediction, special models, such as life cycle cost models of railway vehicles, prediction of the life cycle cost using statistical and artificial neural network methods in conceptual product design and comparison of reliability prediction methods using life cycle cost analysis [7], [8], [9], [10], [11] and [12] might be used. In the first part of the paper, a general approach to the calculation of the life cycle costs of motor vehicles is presented. The second part proposes one of the possible approaches to predicting the life cycle costs of special motor vehicles, based on the company logistics information system.

The essential requirements for vehicle operation today are the sustainability of failurefree operation and life cycle cost minimization. At the same time, the vehicle operation must be safe and with no harmful effects on the environment and road traffic. The decision on vehicle purchase is not only influenced by acquisition costs, but also by operating and maintenance costs during the vehicle lifetime (ownership costs) as well as destruction costs. The aim of this system is to prevent failure occurrence, thereby decreasing maintenance costs [13]. Suppliers could use the presented model for the optimization and assessment of their operating, maintenance and destruction strategies.

There are many methods and models available after the life cycle costs have been predicted. However, individual methods have certain limitations. Different methods are usually required for cost estimations. This methodology shows one of possible approaches to life cycle costing of ground military equipment.

The methods defined as calculation or estimation methods are used for all life cycle stages. Parametric or analogical methods prevail. In the initial stages, decision support methods and system dynamics are becoming popular. This is due to a lack of quantitative historical data. Optimization or simulation models are also used to analyze the system availability and stability of operational and strategic planning of technical systems in the most cost-effective way [14].

It is of utmost importance that activities relating to life cycle costing are cost-effective and balanced with what is really achievable in the given stage of the universal program. Moreover, each model used for the life cycle cost prediction must be verified and validated. Then, it can be trusted that the model is suitable for the set purpose.

\section{Risk and uncertainty of life cycle cost prediction}

One of the most important tasks of the army is to keep the combat readiness of combat vehicles [13]. The life cycle cost prediction is associated with inherent uncertainties and risks. The estimates are often based on a small amount of information and data. The utilized historical samples and data may be confusing, insufficient and often difficult and expensive to obtain. Whatever tool or method is used for estimation, historical observations never coincide with a curve or area, unfortunately they occur above or below the estimated value.

For these reasons, the estimate of life cycle costs is represented as a single number by only one result or observation on the curve of cost probability distribution. The estimate is rather stochastic than deterministic, with uncertainty and risk that determine the distribution shape and variance. For a successful decision-taking process it is desirable to present one meaning of the risk and uncertainty for a given point in the process. 
Uncertainty is indeterminacy or a measure of dispersion of a result. The risk in the context of military systems acquisition is the measure of inability to achieve all determinate targets in terms of defined costs, timetables and technical limitations. It exists in the probability that certain outcomes will not be achieved and that there will be consequences of this failure. The most important phase of the process of risk and uncertainty estimation is data collection and analysis. First, all variables in the cost estimation model subject to risk and uncertainty must be identified. Such variables often comprise simple coefficients and factors as well as sophisticated relationships associated with cost estimation, based on regressive analysis. For each variable, probability distribution must be estimated or given.

\subsection{Life cycle costing}

Data collection produces information needed for life cycle cost modelling, which, when appropriate methodology is applied, can be used for predictions and estimations.

Ideally, the data collection process results in:

- increased quality and accuracy of life cycle cost estimation,

- reduced efforts needed to accomplish the life cycle cost estimation,

- reduced time plan for life cycle cost estimation,

- data acquisition for further studies of the system itself or comparable systems [15].

\subsubsection{Types of data}

Data related to the LCC universal program are concerned with this program parameters that explain and control costs. The LCC universal program enables us to obtain the following time-dependent data needed to complete the LCC model during the special vehicle life cycle:

1. Primary data are acquired from an original source and in the original form and are not changed or modified. Characteristics of the primary data are the best dependability, quality and usability the analyst can obtain. These data come directly from the operation that uses LCC monitoring software programs. The following software packages are well known:

- D-LCC, which is a comprehensive software package for conducting a life cycle cost analysis,

- Life Cycle Cost Analysis from Isograph, which calculates life cycle costs,

- Windchill LCC (formerly Relex LCC), a powerful tool for calculating product life cycle costs,

- Omega PS, which is a globally recognized tool for the analysis of logistical support of products according to the Mil Std 1388 / 2B and Def Stan 00-60 standards.

2. Secondary data are derived from the primary data; they are not obtained directly from the source. As they are derived from the original data, their quality may be lower and they may be less useful. They may be valuable for the cost analyst when combined with other data for the purpose of cross-checking.

3. Objective data are of quantitative nature and are preferred as well as the primary data. This type of data is collected through an official data collection process.

4. Subjective data are based on personal attitude or understanding of the characteristics or conditions of a particular system. These data may not be quantitative and generally provide information needed for the interpretation or validation of objective data [15].

In the early stages of the system life cycle, the data mainly come from comparable systems and universal LCC software programs. It is convenient when the data provider is acquainted with life cycle costing, including how and why things are done and how the data are utilized. Otherwise, data quality will decrease, which will have a negative impact on the estimation. The provider must be thoroughly informed on how the outcomes will be used. 


\subsubsection{Data collection process}

The LCC data collection process should be realized in five basic steps:

1. To understand the whole problem concerned with estimation - the analyst should understand the desired utilization of the estimate and the system life cycle stage.

2. To create a generic cost breakdown structure (GCBS), i.e. to create and record data to find out what kind of data is to be collected.

3. To understand the estimation methods and data collection needs. The cost analyst must define the requirements for cost estimation. The GCBS should be used to set limits, and it should be clear which estimation method will be used.

4. To develop a data collection plan. The cost analyst must develop and implement a data collection plan of acquisition of all kinds of data. The plan should ensure that the cost items from the GSBS are covered. Data sources should be identified for cross-checking. In the end a time plan is developed.

5. Data collection for cost estimation requires a relevant analytical estimate as the estimation process is associated with risks and uncertainties [16], [17].

\subsubsection{Collected data processing}

The data analysis process must be conducted so that mistakes are avoided. The main data analysis operations are the following:

1. Data monitoring: the aim is to identify unusual laws (course). In the cost estimation, attention must be paid to any non-standard data deviation or non-linearity.

2. Data validation: the aim is to examine (verify) data file statistics, examine over-limit data deviations and compare data in the time sequence. If an earlier estimate is available (a rough estimate based on experience, a standard estimate for a similar product or an estimate from earlier life cycle stages), the estimates are compared.

Considering that the primary data can come from various sources, data uniformity cannot be assumed, and therefore a certain degree of normalization is unavoidable. Generally, data normalization comprises changes and adaptations made before the data become usable in the given model. Normalization can have many different forms and specific purposes, e.g.:

- annual inflation - constant prices are used. The inflation rate can be predicted for a short term project.

- determination of mechanisms for increasing or decreasing prices, independently of inflation.

- taxes and subsidies. In the LCC analysis, modification of market prices due to taxing is appropriate only if a substantial difference is expected.

- exchange rate is the rate at which one currency will be changed for another.

\subsection{Calculation of the predicted vehicle life cycle}

An analysis of life cycle costs is an economic analysis of the assessment of the total cost of acquisition, ownership and destruction of a product. It is applicable during the entire life cycle of the product or a life cycle stage or combination of different stages, [2], [6] and [18].

There are five period phases of the motor vehicle life cycle:

1. concept and requirement determination,

2. design and development,

3. manufacture,

4. operating state and maintenance,

5. disposal

$$
\begin{aligned}
& \{\text { - acquisition costs, } \\
& \text { - ownership costs } \\
& \text { - destruction costs. }
\end{aligned}
$$


Generally, the total costs for the above listed phases are acquisition costs, ownership costs and destruction costs [2], [6], and [18]. For the LCC prediction model, I recommend to divide the life cycle costs into four categories:

$$
\begin{aligned}
& \mathrm{LCC}=\mathrm{C}_{\mathrm{P}}+\mathrm{C}_{\mathrm{OM}}+\mathrm{C}_{\mathrm{O}}+\mathrm{C}_{\mathrm{D}}, \\
& L C C_{s}=\frac{L C C}{t},
\end{aligned}
$$

where $L C C$ - the life cycle cost of motor vehicles, $L C C_{s}$ - the specific life cycle cost of motor vehicles, $C_{P}$ - the vehicle purchase cost, $C_{O M}-$ the maintenance cost, $C_{O}$ - the cost of the vehicle in the operating state, $C_{D}$ - the vehicle disposal cost, $t$ - the time of vehicle operation.

\subsubsection{Costs of motor vehicle purchase}

The purchase costs of a vehicle (buying price) can be expressed by the relationship [2], [6] and [18]:

$$
\begin{aligned}
& C_{P}=C_{C D}+C_{D D}+C_{M}+C_{S}+C_{G}, \\
& C S_{P}=\frac{C_{p}}{t},
\end{aligned}
$$

where $C S_{P}$ - the specific vehicle purchase costs, $C_{C D}$ - the conceptualization and requirements definition costs, $C_{D D}$ - the vehicle design and development costs, $C_{M}$ - the production costs, $C_{S}$ - the costs of sales, $C_{G}$ - the costs of repairs during the guarantee period, $t$ - the vehicle operation time.

\subsubsection{Costs of motor vehicle maintenance}

The total costs of the vehicle maintenance consist of the cost of preventive maintenance and the cost of corrective maintenance [2], [6] and [18] as follows:

$$
C_{O M}=C_{O M C}+C_{O M P}
$$

The vehicle maintenance costs consist of the cost of material and the cost of labour as follows:

$$
\begin{aligned}
& C_{O M}=\left(C_{O M C M}+C_{O M C L}+C_{O M C F}\right)+\left(C_{O M P M}+C_{O M P L}+C_{O M P F}\right), \\
& C S_{O M}=\frac{C_{O M}}{t},
\end{aligned}
$$

where $C_{O M}$ - the cumulative maintenance costs, $C_{O M S}-$ the specific cumulative maintenance costs, $C_{O M C}$ - the corrective maintenance costs, $C_{O M P}$ - the preventive maintenance costs, $C_{O M C M}$ - the costs of material used for corrective maintenance, $C_{O M C L}$ - the costs of labour force for corrective maintenance, $C_{O M C F}$ - the costs of workshop equipment used for corrective maintenance, $C_{O M P M}$ - the costs of material used for preventive maintenance, $C_{O M P L}$ - the costs of labour force for preventive maintenance, $C_{O M P F}-$ the costs of workshop equipment used for preventive maintenance, $t$ - the operating time in kilometres.

1. Costs of motor vehicle corrective maintenance

The total amount spent on the corrective maintenance during vehicle operation depends on the number of failure occurrences and on the cost of repairs.

Then, the cost of corrective maintenance $\mathrm{C}_{\text {OMC }}$ can be expressed by equations (9), (11) and (12). To calculate the corrective maintenance costs, at least one of the following parameters must be determined, with respect to the information resulting from the calculation of [2], [19]: 
- failure intensity $z_{(t)}$

$$
\begin{aligned}
& z(t)=\lim _{\Delta t \rightarrow 0+} \frac{E[N(t+\Delta t)-N(t)]}{\Delta t}, \\
& C_{O M C}=\sum_{n=1}^{n=j} z_{(t)} i c_{R} .
\end{aligned}
$$

- the mean time between failures $M T B F$

$$
\begin{aligned}
& M T B F=\frac{t}{n_{f}}, \\
& C_{O M C}=\frac{c_{R}}{M T B F} t .
\end{aligned}
$$

- the mean time between failures $\mathrm{MTBF}_{\mathrm{W}}$, using the Weibull distribution and the Nelson method for the determination of parameters $\alpha, \beta$

$$
C_{O M C}=c_{R} \int_{t_{0}}^{t} \frac{t}{M T B F_{W}} d t
$$

where $C_{O M C}$ - the cumulative corrective maintenance costs during operating time $t, t$ - the operating time in kilometres, $i$ - the determined value of the interval in kilometres, $j-$ the number of determined intervals $i, n_{f}$ - the number of failures during interval $t, z_{(t)}$ - the failure intensity at interval $t, M T B F$ - the mean time between failures, $M T B F_{W}$ - the mean time between failures calculated by the Weibull distribution and using the Nelson method for the determination of parameters $\alpha, \beta ; c_{R}$ - the average cost of one failure repair consisting of material and labour costs.

The mean time between failures calculated by using the Weibull distribution and the Nelson method for the determination of parameters $\alpha, \beta$ is performed as follows:

- Selection of failures according to consequences, division into intervals, and the inclusion of incomplete failure-free files in the calculation.

- The Nelson method is used to calculate the cumulative intensity H (x). It is one of the methods suitable for processing generally censored files. During the long term monitoring of a group of vehicles it will happen that the whole monitored operating time interval $t \in\langle 0, T S\rangle$ disintegrates into two characteristic types of intervals. The first type of intervals are finite intervals that are terminated by a failure (the so called time between failures) and the second type of intervals are infinite intervals that are not terminated, see Fig. 1.

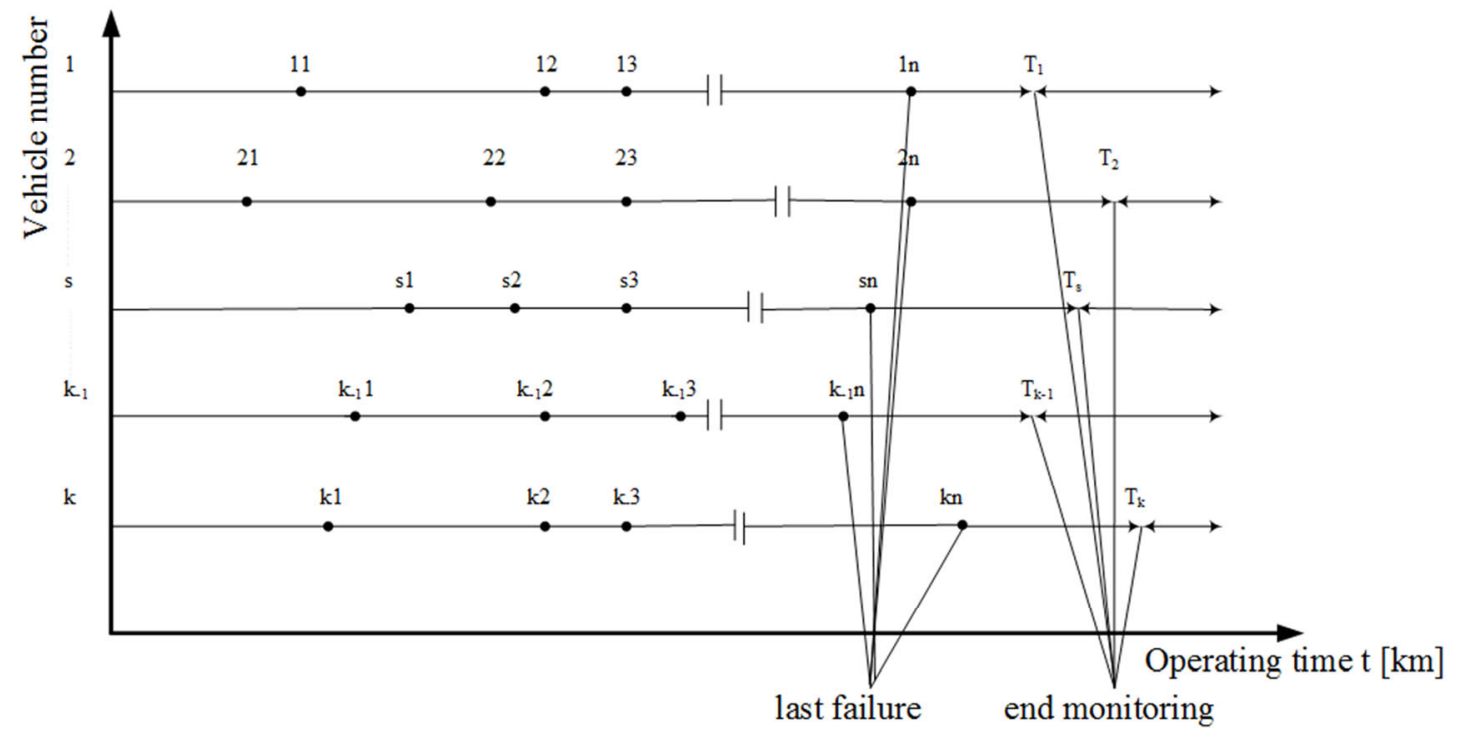

Fig. 1 Intervals between vehicle operation times [20] 


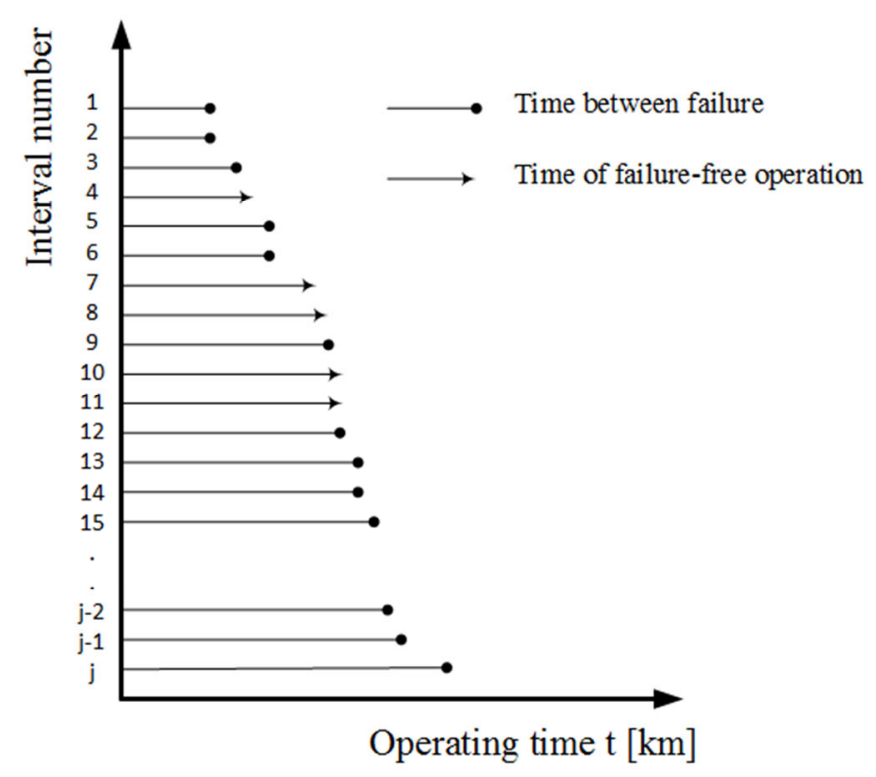

Fig. 2 Generally censored and arranged data file [20]

The entire file of $N$ data on the monitored random variable contains $n$ finite intervals (e.g. in $n$ cases it is the time between failures) and in $N-n$ cases a failure has not yet occurred (intervals of failure-free operation). The $N$ file of values $s_{i}$ will be arranged in an ascending order

$$
\mathrm{s}_{1}{ }^{*} \leq \mathrm{s}_{2}{ }^{*} \leq \mathrm{s}_{3}{ }^{*} \leq \mathrm{s}_{4}{ }^{*} \leq \ldots \ldots \ldots \leq \mathrm{s}_{\mathrm{j}} \ldots \ldots \ldots, \mathrm{s}_{\mathrm{N}}
$$

as shown in Fig. 2.

For items denoted by $*$, empiric intensity of failures $\lambda$ is calculated according to:

$$
\lambda\left(s_{i}^{*}\right)=\frac{1}{N^{*}-j+1} \quad N^{*} \text { pro } s^{*}
$$

and the values

$$
H\left(s_{i}^{*}\right)=\sum_{i=1}^{N} \frac{1}{N^{*}-i+1} .
$$

In this way, we obtained n pairs of values $s_{i}{ }^{*}$ and $H\left(s_{i}{ }^{*}\right)$ that can be processed:

- graphically on logarithmic paper,

- numerically (get W-distribution parameters using the least squares method) [21]

- by using the Weibull diagram to plot cumulative values $H(x)$ independent of time (mileage) $t$.

- by subtracting values $\alpha$ and $\beta$ from the Weibull graph.

- by using the Weibull distribution and the calculated values $\alpha$ and $\beta$ to calculate the mean time between failures [22]

$$
M T B F_{W}=\alpha \Gamma\left(1+\frac{1}{\beta}\right),
$$

- The results will be plotted on the graph, and a regression curve with function representation will be calculated. On the basis of theoretical and practical experience it is proposed to use a regression analysis with special models that are not linearizable, using an exponential trend. The most convenient regression curve will have the following shape [23], [24]:

$$
M T B F_{W_{r}}=b_{1} \cdot e^{-\beta_{1} \cdot t}+b_{2} \cdot e^{-\beta_{2} \cdot t}
$$


where $M T B F_{W r}$ - the mean time between failure in kilometres, $t$ - the operating time in kilometres, $b_{1}, b_{2}$ - the parameter estimates, $\beta_{1}, \beta_{2}$ - the parameter estimates. Some mathematical software, e.g. Matlab, Mathcad, will be used for calculations.

- The mean time between failures during the maximum vehicle lifetime will be calculated from the function equation.

- The two sided confidence interval $\left\langle a_{D}, a_{H}\right\rangle$ will be determined for parameter $\alpha$ with known parameters $\beta, \gamma$ and the confidence coefficient $1-\alpha$ [24]

$$
\begin{aligned}
& a_{D}=\left(\frac{2 \sum_{i=1}^{n}\left(x_{i}-\gamma\right)^{\beta}}{\chi_{1-\frac{\alpha}{2}}^{2}(2 n)}\right)^{\frac{1}{\beta}}, \\
& a_{H}=\left(\frac{2 \sum_{i=1}^{n}\left(x_{i}-\gamma\right)^{\beta}}{\chi_{\frac{\alpha}{2}}^{2}(2 n)}\right)^{\frac{1}{\beta}},
\end{aligned}
$$

where $\chi^{2}(\gamma)$ is value $\chi^{2}$ of the distribution with $\gamma$ degrees of freedom.

Specific costs of corrective maintenance are calculated according to

$$
C S_{O M C}=\frac{C_{O M C}}{t}
$$

Equations (9), (11) a (12) are used to calculate the cumulative maintenance costs for the monitored predicted interval. The calculation based on the mean time between failures $M T B F$ determined as the average interval between failures does not comprise degradation effects and can be determined in the early stages, i.e. in the vehicle design and production. On the other side, the failure rate function $z_{(t)}$ and the mean time between failures $M T B F_{W}$ express the failure rate dependence on the run, i.e. they express material degradation effects. These parameters are not available in the early stages - vehicle design and production - as they are determined by vehicle monitoring.

The obtained data and equations $(8-12)$ are then used to calculate the specific corrective maintenance costs according to formula (19), representing the costs of corrective maintenance for one kilometre of the operation of the ground military equipment.

2. Costs of motor vehicle preventive maintenance

The considered costs comprise the cost of the planned preventive maintenance conducted according to the developed time plan of the given vehicle maintenance.

The total amount to be paid for preventive maintenance during operation depends on the number of preventive maintenance interventions on a vehicle (maintenance interval). The amount also depends on the price range for preventive maintenance costs including the costs of material and the costs of labour. To calculate the cumulative costs and mean cumulative costs for preventive maintenance, we can use the following relationships [2], [6]:

$$
\begin{aligned}
& C_{O M P}=t \hat{c}_{M} \\
& C S_{O M P}=\frac{C_{O M P}}{t}
\end{aligned}
$$

where $C_{O M P}$ - the cumulative costs for preventive maintenance during operating time $\mathrm{t}$, $C S_{O M P}$ - the specific cumulative costs for preventive maintenance during operating time $\mathrm{t}$, $t$ - the operating time in kilometres, $\hat{c}_{M}$ - the average costs of preventive maintenance including cost of material and cost of labour, related to the unit of operating time $(\mathrm{km})$. 
To calculate the predicted costs of preventive maintenance, the following values are determined:

- service inspection interval $(\mathrm{km})$

- time of service interval (years)

- types of service inspection - guarantee (gsi), 1st degree (si1), 2nd degree (si2), 3rd degree (si3).

The above values are used to calculate the following indicators:

- cost of guarantee service inspection (cost) - $C_{g s i}$,

- costs of individual types of service inspection (cost) - $C_{s i 1}, C_{s i 2}, C_{s i 3}$,

- costs of service inspections during operating time (cost) - $C_{S s i}$,

$$
C_{S s i}=C_{s i 1}+C_{s i 2}+C_{s i 3}
$$

- specific costs of service inspection $C S_{S s i}(\operatorname{cost} / \mathrm{km})$ for a kilometre of operation

$$
C S_{S s i}=\frac{C_{S s i}}{t} .
$$

After the service inspection, most producers determine two parameters:

- service inspection interval in $\mathrm{km}-p_{k m}$,

- service inspection interval in years $-p_{y}$.

In reality, the type of service inspection that occurs earlier is conducted as follows:

- The planned service inspection interval in $\mathrm{km}$ ends earlier than the service inspection interval in years. Then the costs will be calculated according to (22) and the specific costs according to (23).

- The planned service inspection interval in $\mathrm{km}$ ends later than the planned service inspection interval in years. Therefore, the service inspection will be conducted in accordance with the time service interval. The costs will be calculated according to (22). To calculate the average costs of service inspection, we first need to get the average annual operating time $\left(p_{a k m}\right)$, if $p_{a k m}<p_{k m}$. Then, the mean costs of service inspection can be calculated according to (24).

$$
C S_{S s i}=\frac{p_{k m}}{p_{a k m}} \frac{C_{S s i}}{t}
$$

The supplied data and equations (22) are used to calculate the specific costs of preventive maintenance according to (23) and (24), representing the costs of preventive maintenance related to one kilometre of special motor vehicle operation.

\subsubsection{Operating costs of motor vehicle}

Operating costs $C_{O}$ cover the costs of fuel $C_{F}$, operating fluids, oils and lubricants $C_{O L}$ that are supplied during vehicle operation (not during service inspection), tyres $C_{T}$, batteries $C_{A B}$, vehicle insurance fee and road tax or other mandatory fees $C_{I R T}$, cost of the motorway tax sticker $C_{M T}$, mandatory vehicle inspection and emission measurement in special vehicles $C_{E T C}$ and vehicle superstructure $\operatorname{cost} C_{V B}$. The costs are calculated according to:

$$
C_{O}=C_{F}+C_{O L}+C_{T}+C_{A B}+C_{I R T}+C_{M T}+C_{E T C}+C_{V B} .
$$

For the proposed model, we need to calculate annual specific costs related to one kilometre. Relationships (26) - (34) will be used as follows:

$$
\begin{aligned}
& C S_{O}=C S_{F}+C S_{O L}+C S_{T}+C S_{A B}+C S_{I R T}+C S_{M T}+C S_{T C}+C S_{E}+C S_{V B} \\
& C S_{F}=\frac{C_{F}}{t}=\frac{c_{F} p_{F}}{t} \cong \frac{\frac{c_{a F}}{100} p_{F} t}{t}
\end{aligned}
$$




$$
\begin{aligned}
& C S_{O L}=\frac{C_{O L}}{t}=\frac{c_{O L} p_{O L}}{t} \cong \frac{\frac{c_{a O L}}{100} p_{O L} t}{t} \\
& C S_{T}=\frac{C_{T}}{t}=\frac{n_{T n} p_{T}}{t} \cong \frac{\frac{t}{d_{a T}} n_{T} p_{T}}{t} \\
& C S_{A B}=\frac{C_{A B}}{t}=\frac{n_{A B n} p_{A B}}{t}=\frac{\frac{t}{d_{a A B}} n_{A B} p_{A B}}{t} \\
& C S_{I R T}=\frac{C_{I R T}}{t}=\frac{\left(C_{I}+C_{R T}\right) y_{n}}{t} \cong \frac{\left(\frac{C_{I}+C_{R T}}{t_{a y}}\right) t}{t} \\
& C S_{M T}=\frac{C_{M T}}{t}=\frac{c_{M T} y_{n}}{t} \cong \frac{\left(\frac{c_{M T}}{t_{a y}}\right) t}{t} \\
& C S_{E T C}=\frac{C_{T C}+C_{E}}{t}=\frac{\left(c_{T C}+c_{E}\right) n_{E T C}}{t} \cong \frac{\left(\frac{\left(c_{T C}+c_{E}\right) / y_{v}}{t_{a y}}\right) t}{t} \\
& C S_{V B}=\frac{C_{V B}}{t}=\frac{p_{O U} n_{O U}}{t} \cong \frac{\left(\frac{p_{O U} n_{O U a y}}{t_{a y}}\right) t}{t}
\end{aligned}
$$

where $C S_{O}$ - the specific operating cost (cost $\left./ \mathrm{km}\right), c_{F}$ - the fuel consumption (l), $c_{a F}$ - the average fuel consumption $(1 / 100 \mathrm{~km}), p_{F}$ - the price of fuel (price/l), $t$ - the operating time $(\mathrm{km})$, $c_{O L}$ - the oil and lubricant consumption (1), $c_{a O L}$ - the average oil and lubricant consumption $(1 / 100 \mathrm{~km}), p_{O L}-$ the price of oil and lubricant (price/l), $d_{a T}$ - the average tyre life $(\mathrm{km}), n_{T}-$ the number of tyres per vehicle (pcs), $n_{T n}$ - the number of tyres for operating time $\mathrm{t}(\mathrm{pcs}), p_{T}-$ the price of a tyre (price), $d_{a A B}$ - the average battery $(\mathrm{km}), n_{A B}$ - the number of batteries per vehicle (pcs), $n_{A B n}$ - the number of batteries for operating time (pcs), $p_{A B}$ - the battery price (price), $C_{I}$ - the cost of annual vehicle insurance fee (cost), $C_{R T}$ - the cost of annual road tax (cost), $y_{n}$ - the number of vehicle operation years $(-), t_{a y}-$ the average annual operating time $(\mathrm{km})$, $c_{M T}$ - the cost of annual motorway tax sticker (price), $c_{E}$ - the cost of one mandatory emission control (cost), $c_{T C}$ - the cost of one mandatory technical vehicle inspection (cost), $p_{E T C}$ - the price of a mandatory emission measurement and vehicle inspection (price), $n_{E T C}$ - the number of mandatory emission measurements and vehicle inspections during operating time (pcs), $y_{v}$ - the number of years of mandatory emission measurement and vehicle inspection validity (-), $n_{O U}$ - the number of superstructure operating units (operating units), $p_{O U}-$ the price of one superstructure average annual number of superstructure operating units (operating units).

Using the obtained data and equations $(27$ - 34) the specific operating costs are calculated according to formula (26), representing the costs for one kilometre of ground military equipment operation.

\subsubsection{Disposal costs of motor vehicle}

This category includes the costs of the disposal and destruction of end-of-life vehicles [2], [6], and [18], for which it applies

$$
\mathrm{C}_{\mathrm{D}}=\mathrm{C}_{\mathrm{DD}}+\mathrm{C}_{\mathrm{DR}}
$$

where $C_{D D}$ - the costs of dismantling and removing engineering parts, $C_{D R}$ - the costs of recycling or safe disposal.

The cost of destruction can have a plus or a minus value. The plus value is attained when the vehicle is dismantled and its parts are reused as raw materials. On the other hand, the negative value is attained when the vehicle is ecologically disposed of by another company [6]. 


\section{Prediction of special motor vehicle ownership costs}

In this chapter, a simplified model for predicting the ownership cost of special motor vehicles used in construction and agricultural industries, and particularly in the military environment, is introduced. For this prediction it is necessary to have a logistic information system with an implemented regular data collected system. The ownership cost might be calculated only if the information system preserves the ownership data for at least three years.

The model is proposed so that the prediction of the special motor vehicle ownership cost could be simplified during subsequent years, otherwise complex mathematical relations would have to be used. Another problem is to calculate the future ownership cost of corrective maintenance. This approach helps us to avoid the problems and the prediction can be even more accurate. The important aspect is the input data of special motor vehicle operation which are continuously entered into the information system.

For these reasons, it is proposed to divide the costs into two separate parts:

1. Cost of the operation of the special motor vehicle chassis and superstructure:

- fuel, including change of oil during preventive maintenance,

- annual mandatory insurance of ground military equipment,

- mandatory emission measurement and technical inspection,

- costs of superstructure operating units (hours of superstructure operation, number of shots, etc.).

2. Cost of the maintenance (preventive and corrective) of the special motor vehicle chassis and superstructure :

- batteries,

- tyres,

- material and labour needed for the preventive maintenance of the vehicle chassis - air filters, oil filters, etc.,

- material and labour needed for the preventive maintenance of the superstructure,

- material and labour needed for the corrective maintenance of the vehicle chassis - air filters, oil filters, etc.,

- material and labour needed for the corrective maintenance of the superstructure.

To predict the future costs $r_{+1}$, it is recommended to consider the preceding three years $\left(r_{-3,}, r_{-2}\right.$, and $\left.r_{-1}\right)$. Also, to be able to monitor the preceding three years more reliably, I propose to use the weighted moving averages. The weights will be assigned as follows:

- the highest weight -3 will be assigned to year $r_{-1}$,

- the middle weight -2 will be assigned to year $r_{-2}$,

- the lowest weight -1 will be assigned to year $r_{-3}$.

In this way, the significance of individual preceding years will be taken into account. If necessary, the weights can be changed for serious reasons (e.g. year $r_{-2}$ will be similar to the next year).

\subsection{Cost prediction for operation of motor vehicle chassis and superstructure}

When calculating the costs of the operation of the vehicle chassis and superstructure, we can proceed in two ways. The following relationships are suggested for the calculation:

1. To calculate the costs of cumulative vehicle chassis operation $C_{O_{b m}}$ for times $r_{-3}$, $r_{-2}$, and $r_{-1}$ according to

$$
C_{O_{b m}}=\left(1 C_{O_{b m_{r-3}}}+2 C_{o_{b m_{r-2}}}+3 C_{O_{b m_{r-1}}}\right) / 6 .
$$


2. To calculate the specific costs of vehicle chassis operation $C S_{O_{b m}}$ according to

$$
C S_{O_{b m}}=\frac{C_{O_{b m}}}{t}
$$

where $t$ - the mileage for times $r_{-3,} r_{-2}$, and $r_{-1}$.

3. To make the cumulative cost prediction for vehicle chassis operation $C_{O_{b m_{r+1}}}$ for the following year $r_{+1}$ according to

$$
C_{O_{b m_{r+1}}}=\left(C S_{O_{b m}} \times t_{r+1}\right) c_{i} c_{i d}
$$

where $t_{r+1}$ - the predicted mileage for the following year $r_{+1}$.

4. When necessary, the following coefficients can be introduced:

- inflation coefficient $c_{i}$ (example: $2 \%$ inflation - coefficient 1.02),

- coefficient of data collection inaccuracy $c_{i d}$. It is likely that the required data file will be incomplete, then the coefficient would be 1 to 1.3 (not all data are presented).

5. To calculate the cumulative vehicle superstructure costs $C o_{v b}$ for times $r_{-3}, r_{-2}$, and $r_{-1}$ according to

$$
C_{O_{v b}}=\left(1 C_{O_{v b_{r-3}}}+2 C_{O_{v b_{r-2}}}+3 C_{O_{v b}-1}\right) / 6
$$

6. To calculate the specific vehicle superstructure operating costs $C S_{O_{v b}}$ according to

$$
C S_{O_{v b}}=\frac{C_{O_{v b}}}{t}
$$

where $t$ - the mileage for times $r_{-3,} r_{-2}$, and $r_{-1}$.

7. To make the estimation of the cumulative costs of superstructure operation $C_{O_{v b}}$ for the following year $r_{+1}$ for the vehicle chassis operation according to

$$
C_{O_{v b_{r+1}}}=\left(C S o_{v b} \times t_{r+1}\right) c_{i} c_{i d}
$$

where $t_{r+1}$ - the predicted mileage for the year $r_{+1}$.

8. When necessary, relevant coefficients can be introduced, e.g.:

- inflation coefficient $c_{i}$,

- coefficient of data collection inaccuracy $c_{i d}$.

9. The total predicted cumulative costs of the operation of the motor vehicle chassis and superstructure will be

$$
C_{O_{b m v b_{r+1}}}=C_{O_{b m_{r+1}}}+C_{O_{v b_{r+1}}} \text {. }
$$

3.2 Cost prediction of maintenance of motor vehicle chassis and superstructure

This is the cost of comprehensive maintenance, which will be carried out on the motor vehicle chassis and superstructure. It will be based on the previous three years, as in the previous section, including the use of weights for the previous years.

I propose to proceed according to the following formulae:

1. To calculate the cumulative costs of maintenance of the motor vehicle chassis $C_{M_{b m}}$ for times $r_{-3}, r_{-2}$, and $r_{-1}$ according to

$$
C_{M_{b m}}=\left(1 C_{M_{b m_{r-3}}}+2 C_{M_{b m_{r-2}}}+3 C_{M_{b m_{r-1}}}\right) / 6
$$


2. To calculate the specific costs of maintenance of the motor vehicle chassis $C S_{M_{b m}}$ according to

$$
C S_{M_{b m}}=\frac{C_{M_{b m}}}{t}
$$

where $t$ - the mileage for times $r_{-3}, r_{-2}$, and $r_{-1}$.

3. To make prediction of cumulative costs of maintenance of the motor vehicle chassis $C_{M_{b m_{r+1}}}$ for times $r_{+1}$ according to

$$
C_{M_{b m_{r+1}}}=\left(C S_{M_{b m}} \times t_{r+1}\right) c_{i} c_{a_{b m}} c_{i d}
$$

where $t_{r+1}$ - the predicted mileage for the year $r_{+1}$.

4. When necessary, the following coefficients can be introduced, e.g.

- inflation coefficient $c_{i}$,

- aging coefficient of motor vehicle chassis $c_{a b m}$. This might be divided into three stages. During the first motor vehicle life stage the expected vehicle aging coefficient equals 1 . During the second and the third life stage the coefficient is expected to increase taking into account the experience from a similar vehicle type (e.g. when considering a military vehicle life to be 20 years, during the first six years the coefficient will be 1; during the second period of the motor vehicle life ( $7-15$ years) the failure rate is expected to increase by $1.5 \%$ every year; during the third period of the motor vehicle life the failure rate (cost) is expected to increase by $3 \%$ every year),

- coefficient of data collection inaccuracy $c_{i d}$.

5. To calculate the cumulative costs of maintenance of the motor vehicle superstructure $C_{M_{v b}}$ for times $r_{-3,} r_{-2}$, and $r_{-1}$ according to

$$
C_{M_{v b}}=\left(1 C_{M_{v b_{r-3}}}+2 C_{M_{v b_{r-2}}}+3 C_{M_{v b}-1}\right) / 6 .
$$

6. To calculate the specific costs of maintenance of the motor vehicle superstructure $C S_{M_{v b}}$ according to

$$
C S_{M_{v b}}=\frac{C_{M_{v b}}}{t}
$$

where $t$ - the mileage for times $r_{-3,} r_{-2}$, and $r_{-1}$.

7. To make prediction of cumulative costs of maintenance of the motor vehicle superstructure $C_{M_{v b_{r+1}}}$ for times $r_{+1}$ according to

$$
C_{M_{v b}+1}=\left(C S_{M_{v b}} \times t_{r+1}\right) c_{i} c_{a_{v b}} c_{i d}
$$

where $t_{r+1}$ - the predicted mileage for year $r_{+1}, c_{a v b}$ - the aging coefficient of the motor vehicle superstructure.

\subsection{Prediction of ownership costs of special motor vehicles}

To predict the ownership life cycle costs, a calculation is performed according to the following mathematical relationship for each type of a special vehicle

$$
L C C_{P_{i}}=C_{O_{b m v b_{r+1}}}+C_{M_{b m v b_{r+1}}} .
$$

Subsequently, a summary of the predicted life cycle cost of each type of the special motor vehicle is determined by the following relationship 


$$
L C C_{P}=\sum_{i=1}^{i=n} L C C_{P_{i}}
$$

where $n$ is the number of special motor vehicle types.

3.4 Example of prediction of ownership costs of a special motor vehicle

Here is an example of prediction of the life cycle cost of ownership, which is based on the following input data. The special vehicle has a chassis and a superstructure. The input parameters are as follows:

- the millage of the vehicle chassis is $r_{-3}=11200 \mathrm{~km} ; r_{-2}=12300 \mathrm{~km} ; r_{-1}=12100$ $\mathrm{km}$;

- the costs of the operation of the vehicle chassis are $C_{O_{b m_{r-3}}}=3704$ Euro; $C_{O_{b m_{r-2}}}$ $=4259$ Euro; $C_{O_{b m_{r-1}}}=4370$ Euro;

- the costs of the maintenance of the vehicle chassis are $C_{M_{b m_{r-3}}}=2800$ Euro; $C_{M_{b m_{r-2}}}=3100$ Euro; $C_{M_{b m_{r-1}}}=3200$ Euro;

- the hours of operation of the vehicle superstructure are $r_{-3}=366 ; r_{-2}=400 ; r_{-1}=350$;

- the costs of operation of the vehicle superstructure are $C_{O_{v b}-3}=5200$ Euro; $C_{O_{v b_{r-2}}}=5600$ Euro; $C_{O_{v b_{r-1}}}=5200$ Euro;

- the costs for maintenance of the vehicle superstructure are $C_{M_{v b_{r-3}}}=800$ Euro; $C_{M_{v b_{r-2}}}=890$ Euro; $C_{M_{v b_{r-1}}}=800$ Euro;

- the inflation in the past ten years is $2 \%, c_{i}=1.02$;

- the coefficient of age is $r_{-1}$ to $r_{-3}=1.0 ; r_{-4}$ to $r_{-10}=1.5$;

- version 1 with coefficient of inaccuracy $c_{i d}=1.05$;

- version 2 with coefficient of inaccuracy $c_{i d}=1.30$.

Based on the above input data, a model of cost prediction for the next ten years was created in two versions (Fig. 3), which depend on the accuracy of the input data.

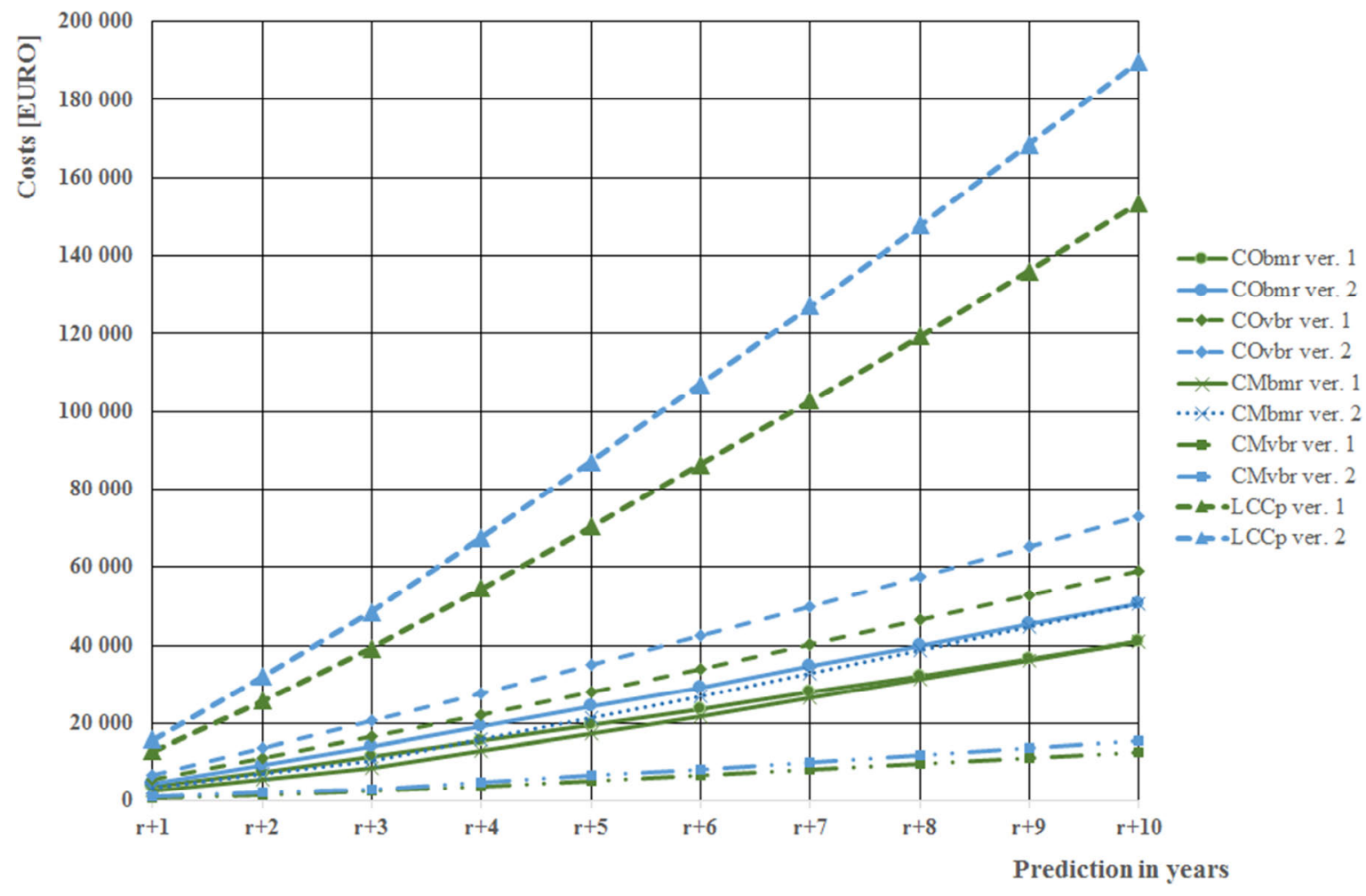

Fig. 3 Prediction of ownership costs of the life cycle of a special motor vehicle 


\section{Conclusion}

The estimation of the life cycle cost is always connected with uncertainty and risk. The estimations are often based on a low number of information and data. Also, they are sometimes based on the past data samples which are mostly chaotic, limited, and difficult and expensive to get. Some information is very often not available, e.g. mean time between failures or failure intensity used for calculating the maintenance cost after the failure. Therefore, the introduced solution has been proposed for the prediction of the special motor vehicle ownership cost. In this way, the prediction will be quite simple and no special software to calculate the predicted motor vehicle ownership cost needs to be purchased. What is more, the analyzed data processed during previous years might be used for assessing the optimization of special motor vehicle life period. However, it is necessary to have a working and regularly updated company logistic information system and a back-up of relevant data for at least three years. It would be useful to develop the proposed mathematical model for the prediction of the motor vehicle ownership cost in the Matlab software environment or in a relevant spreadsheet program.

\section{Acknowledgement:}

The presented study has been prepared with the support of the Ministry of Defence of the Czech Republic, Partial Project for Institutional Development, K-202, Department of Combat and Special Vehicles of the University of Defence, Brno.

\section{REFERENCES}

[1] Y. Asiedu, P. Gu. Product life cycle cost analysis: state of the art review. International Journal of Production Research 1998; 36(4): 883-908. https://doi.org/10.1080/002075498193444

[2] Furch, J. Design of Operational Vehicle Maintenance Programme Based on Life Cycle Cost and Reliability Centred Maintenance. Advances in Military Technology. 2009, vol. 4, no. 2, p. 37-54.

[3] Mai Z. Q., Xu T. T., Sun L., Wang X. L., Fan J. M., Sun A. Q. Cost Estimation of Product Life Cycle. Proceedings of the Second International Conference on Advances in Materials and Manufacturing Processes 2011; 582-585.

[4] Thaduri A., Verma A. K., Kumar U. Comparison of reliability prediction methods using life cycle cost analysis. Proceedings of the Fifty-ninth Annual Reliability and Maintainability Symposium 2013. https://doi.org/10.1109/rams.2013.6517747

[5] Vintr Z., Vintr D. Vehicle maintenance process optimisation using life cycle costs data and reliabilitycentred maintenance. Proceedings of the First International Conference on Maintenance Engineering 2006; 180-188

[6] Furch, J. A model for predicting motor vehicle life cycle cost and its verification. Transactions of FAMENA, 2016, vol. 40, no. 1, p. 15-26. ISSN 1333-1124.

[7] Chovanec A. Analysing and modelling off-road vehicle availability. Proceedings of the Sixteenth International Conference on Transport Means 2012; 54-57.

[8] Jun H. K., Kim J. H. Life cycle cost modeling for railway vehicle. Proceedings of International Conference on Electrical Machines and Systems 2007; 588-593.

[9] Leitner B. A new approach to identification and modelling of machines dynamic systems behaviour. Proceedings of the Fourteenth International Conference on Transport means 2010; 17-20.

[10] Seo K. K., Park J. H., Jang D. S., Wallace D. Prediction of the life cycle cost using statistical and artificial neural network methods in conceptual product design. International Journal of Computer Integrated Manufacturing 2002; 15(6): 541-554. https://doi.org/10.1080/09511920210143417

[11] Thaduri A., Verma A. K., Kumar U. Comparison of reliability prediction methods using life cycle cost analysis. Proceedings of the Fifty-ninth Annual Reliability and Maintainability Symposium 2013. https://doi.org/10.1109/rams.2013.6517747

[12] Waghmode L. Y., Sahasrabudhe A. D. On the expected number of failures and maintenance cost prediction of repairable systems from life cycle cost modeling perspective. Proceedings of the ASME International Design Engineering Technical Conferences and Computers and Information in Engineering Conference 2010; 553-560. https://doi.org/10.1115/detc2010-28044 
[13] Furch, J., Krobot, Z., Št’astný, J., Túró, T. Using Telemetry for Maintenance of Special Military Vehicles. In: Modelling and Simulation for Autonomous Systems. 2017: Springer International Publishing, 2018, p. 392-401. ISBN 978-3-319-76071-1. https://doi.org/10.1007/978-3-319-76072-8_28

[14] RTO-TR-SAS-054. Methods and Models for Life Cycle Costing. Springfield: National Technical Information Service, 2007.

[15] ALCCP-1. NATO Guidance on life cycle costs. Springfield: National Technical Information Service, 2008.

[16] AAP-48:2013. NATO System Life Cycle Stages and Processes. Springfield: National Technical Information Service, 2013.

[17] RTO MP-096/SAS-036. Cost Structure and Life Cycle Cost for Military Systems. Springfield: National Technical Information Service, 2003.

[18] ČSN EN 60300-3-3. Dependability management: Part 3-3: Application guide - Life cycle costing. Praha: ČNI.

[19] Furch, J., Determination of Vehicle Durability Based on Life Cycle Costs and Failure Intensity. In: Intelligent Technologies in Logistics and Mechatronics Systems ITELMS'2010. Kaunas: Kaunas University of Technology, 2010, s. 23-26. ISBN 978-9955-25-836-0.

[20] Nelson, W. Theory and Applications of Hazard Plotting for Censored Failure Data. Technometrics [online]. 2000, 42(1), 12-25 [cit. 2019-04-05]. https://doi.org/10.1080/00401706.2000.10485975. ISSN 0040-1706. Dostupné z: http://www.tandfonline.com/doi/abs/10.1080/00401706.2000.10485975

[21] Arkin M., Bradford L. and Leemis L. M. Nonparametric Estimation of the Cumulative Intensity Function for a Nonhomogeneous Poisson Process from Overlapping Realizations. Management Science [online]. 2000, 46(7), 989-998 [cit. 2019-04-05]. https://doi.org/10.1287/mnsc.46.7.989.12037. ISSN 0025-1909.

[22] Rinne, H. The Weibull Distribution [online]. Boca Raton: Chapman and Hall/CRC, 2008 [cit. 2019-0405]. https://doi.org/10.1201/9781420087444. ISBN 978-1-4200-8743-7.

[23] Vintr, Z. Rational Design of Conditions for Reliability Test. In: The Proceedings of $8^{\text {th }}$ International Conference on Reliability, Maintainability and Safety - ICMRS 2009. New York: IEEE, 2009, pp. 363 366. https://doi.org/10.1109/icrms.2009.5270173

[24] Vintr, Z. Reliability Test Parameters. In: Transport Means 2014 - Proceedings of 18th International Conference. Kaunas: Kaunas University of Technology, 2014, pp. 304-307.

Submitted: $\quad 23.5 .2019$

Accepted: $\quad 28.9 .2020$
Prof. Eng. Jan Furch, Ph.D.

Department of Combat and Special

Vehicles

University of Defence

Kounicova str., 65, Czech Republic

E-mail: jan.furch@unob.cz 